\title{
Inflammatory cytokine response to exercise in alpha-1-antitrypsin deficient COPD patients 'on' or 'off' augmentation therapy
}

\author{
I Mark Olfert ${ }^{*}$, Moh H Malek ${ }^{2,3}$, Tomas ML Eagan ${ }^{3,4}$, Harrieth Wagner ${ }^{3}$ and Peter D Wagner ${ }^{3}$
}

\begin{abstract}
Background: There is still limited information on systemic inflammation in alpha-1-antitrypsin-deficient (AATD) COPD patients and what effect alpha-1-antitrypsin augmentation therapy and/or exercise might have on circulating inflammatory cytokines. We hypothesized that AATD COPD patients on augmentation therapy (AATD + AUG) would have lower circulating and skeletal muscle inflammatory cytokines compared to AATD COPD patients not receiving augmentation therapy (AATD-AUG) and/or the typical non-AATD (COPD) patient. We also hypothesized that cytokine response to exercise would be lower in AATD + AUG compared to AATD-AUG or COPD subjects.
\end{abstract}

Methods: Arterial and femoral venous concentration and skeletal muscle expression of TNFa, IL-6, IL-1 $\beta$ and CRP were measured at rest, during and up to 4-hours after 50\% maximal 1-hour knee extensor exercise in all COPD patient groups, including 2 additional groups (i.e. AATD with normal lung function, and healthy age-/activity-matched controls).

Results: Circulating CRP was higher in AATD + AUG $(4.7 \pm 1.6 \mathrm{mg} / \mathrm{dL})$ and AATD-AUG $(3.3 \pm 1.2 \mathrm{mg} / \mathrm{dL})$ compared to healthy controls $(1.5 \pm 0.3 \mathrm{mg} / \mathrm{dL}, \mathrm{p}<0.05)$, but lower in AATD compared to non-AATD-COPD patients $(6.1 \pm 2.6 \mathrm{mg} / \mathrm{dL}$, $p<0.05)$. TNFa, IL-6 and IL-1 $\beta$ were significantly increased by 1.7-, 1.7-, and 4.7-fold, respectively, in non-AATD COPD compared to AATD COPD $(p<0.05)$, and 1.3-, 1.7-, and 2.2-fold, respectively, compared to healthy subjects $(p<0.05)$. Skeletal muscle TNFa was on average 3-4 fold greater in AATD-AUG compared to the other groups $(p<0.05)$. Exercise showed no effect on these cytokines in any of our patient groups.

Conclusion: These data show that AATD COPD patients do not experience the same chronic systemic inflammation and exhibit reduced inflammation compared to non-AATD COPD patients. Augmentation therapy may help to improve muscle efflux of TNFa and reduce muscle TNFa concentration, but showed no effect on IL-6, IL-1 $\beta$ or CRP.

Keywords: Tumor necrosis factor-a, C-reactive protein, Skeletal muscle, Emphysema, Inflammation

\section{Background}

Alpha-1 antitrypsin deficiency (AATD) is an inherited genetic disorder that leads to development of emphysema resulting in chronic obstructive pulmonary disease (COPD) among other complications (e.g. liver dysfunction). The lack of functional $\alpha_{1}$-antitrypsin exposes the lungs to an insufficient inhibition of serine protease activity leading to chronic uncontrolled proteolytic attack that results in early-life ( $<40$ years of age) alveolar destruction, which can occur independent of environmental risk factors, such as

\footnotetext{
* Correspondence: molfert@hsc.wvu.edu

${ }^{1}$ Center for Cardiovascular and Respiratory Sciences, Division of Exercise Physiology, One Medical Center Dr, West Virginia University School of Medicine, Morgantown, WV 26506-9105, USA

Full list of author information is available at the end of the article
}

cigarette smoke. Since the first report identifying the connection between abnormal alpha-1 antitrypsin and COPD in 1963 [1], more than 90 different $\alpha_{1}$-antitrypsin phenotypes have been described. The most common protein inhibitor $(\mathrm{Pi})$ variants are the $\mathrm{M}, \mathrm{S}$, and $\mathrm{Z}$ alleles, with the PiMM representing normal genotype and PiMS, PiSS, PiMZ, PiZS and PiZZ representing genotypes of increasing severity for abnormal circulating $\alpha_{1}$-antitrypsin concentration (ranging from 20\% loss in PiMS to $>85 \%$ loss in PiZZ individuals) [2]. The rates of decline in lung function and onset of emphysema can be highly variable in AATD individuals, in part due to phenotypic differences in $\alpha_{1}$-antitrypsin reductions; but also due to varying individual 
exposures to environmental risk factors (most notably cigarette smoke history) $[3,4]$.

In people with normal circulating AAT levels, environmental irritants (such as cigarette smoke, coal dust, etc.) induces acute and chronic airway inflammation that plays a prominent role in development and progression of COPD [5]. Systemic inflammation is also prevalent in many patients with COPD [6,7], but it remains controversial whether systemic inflammation represents 'spill over' from the lung inflammation or activation of a chronic systemic process [8]. Irrespective of the source, elevated circulating levels of inflammatory biomarkers, such as tumor necrosis factor-alpha (TNF $\alpha)$, C-reactive protein (CRP), interleukin (IL)-6, and IL-1 $\beta$ have all been associated with severity and exacerbations of COPD and may contribute to comorbidities accompanying COPD [9-11]. In patients with AATD COPD, there is evidence that abnormal alleles of $\alpha_{1}$-antitrypsin can produce polymers that can act as neutrophil chemoattractants (such as $\mathrm{Pi}^{\mathrm{i}} \mathrm{Z}$ ' polymers) which may contribute to a pro-inflammatory state and development of emphysema [12,13], and is consistent with increased expression of pulmonary inflammatory mediators in AATD individuals [14-16]. In addition, PiMZ subjects without airway obstruction may also exhibit neutrophilic inflammation in their airways, and therefore at greater risk in developing pulmonary changes [15]. Indeed, native $\alpha_{1}$-antitrypsin (AAT) serves as an endogenous inhibitor of proinflammatory cytokine production $[17,18]$, implying that loss or reductions in AAT concentration could make AATD individuals more susceptible to chronic systemic inflammation. Management of AATD patients with COPD can also include treatment with purified AAT to replace/ augment circulating AAT levels, commonly referred to as 'augmentation therapy'. Some evidence suggests that augmentation therapy may reduce airway inflammation [14,19-22] and potentially decrease the progression of COPD symptoms [23]. To our knowledge, however, there are no studies that have compared circulating and skeletal muscle inflammatory cytokines in AATD patients 'on' versus 'off' augmentation therapy, or in individuals with AATD with normal lung function.

Exercise is commonly prescribed as part of the medical treatment plan for patients with COPD. While the benefits of exercise to the immune system [24] and to cardiovascular health are widely recognized, exercise is also known to stimulate increases in pro-inflammatory cytokines, such as TNF $\alpha$ and IL-6 [25]. In healthy individuals, the magnitude and duration of these increases are off-set by similar increases in anti-inflammatory cytokines [25-27]. One concern for patients with COPD is that the combination of exercise and an already elevated circulating inflammatory cytokine level may prove more harmful than good. Previous studies have reported on the effects of exercise and expression of circulating inflammatory mediators in non-AATD patients with COPD showing either increased [28-31] or no change [32-36] in circulating cytokines with exercise. No studies, thus far, have assessed these responses to exercise in AATD individuals with or without COPD, and whether or not augmentation therapy affects the circulating and/or skeletal muscle expression of inflammatory cytokines response to exercise.

Accordingly, to better understand the potential influence of augmentation therapy on biomarkers of systemic inflammation, and the relative risk of exercise contributing to chronic systemic inflammation in AATD individuals, we examined systemic expression of several key inflammatory cytokines in AATD COPD patients receiving and not receiving augmentation therapy, as well as AATD individuals without evidence of obstructive airway disease. Our evaluation also included two control groups: non-AATD COPD patients (with normal $\alpha_{1}$-antitrypsin levels), and age-matched healthy control subjects. We hypothesized, under resting conditions, $\alpha_{1}$-antitrypsin replacement therapy in AATD patients would result in lower expression of circulating and skeletal muscle inflammatory cytokines, compared to the other AATD individuals and/or the traditional (non-AATD) COPD patients. We also hypothesized that circulating cytokine response to exercise would be lower in AATD patients receiving $\alpha_{1}$-antitrypsin replacement therapy compared to COPD or the other AATD subjects.

\section{Methods}

\section{Subjects}

AATD subjects $(n=16)$ were recruited by a national advertisement campaign in the US and brought to the Human Research Laboratory at the Division of Physiology, University of California, San Diego. Exclusion criteria included history of lung disease (other than COPD), cardiovascular disease, diabetes mellitus or any other metabolic diseases, cancer, oral corticosteroid use in the last 6 months, and/or respiratory tract infection within the last 4 weeks, as determined by medical history and patient's list of medication. Presence of COPD was defined according Global Initiative for Chronic Obstructive Lung Disease (GOLD) 2009 COPD guidelines (www.goldcopd.org). Inclusion criteria for AATD subjects were ZZ or SZ genotype with or without history of COPD, whereas control subjects genotype were $\mathrm{MM}$ or MZ genotype. AATD patients were grouped into 3 categories, AATD with COPD receiving augmentation therapy (AATD + AUG, $n=6$ ), AATD with COPD not receiving augmentation therapy (AATD-AUG, $n=6$ ), and AATD with normal lung function (AATD PFTnorm, $n=4$ ). Control COPD patients (with normal $\alpha_{1}$-antitrypsin concentration levels, $\mathrm{n}=7$ ) and healthy control subjects 
$(n=6)$ were recruited by advertisement within the Southern California region. Healthy control subjects were matched for age, sex, and claimed to not participate in regular structured exercise (i.e. running, cycling, etc.) or sport activity. All participants were screened for $\alpha_{1}$-antitrypsin genotyped from a blood sample and had circulating AAT concentration measured (Biocerna LLC, Gaithersburg, MD) (Table 1). All subjects, except for some in the non-AATD COPD group, indicated they were either no longer smoking (at least $>1$ year) or had never smoked. Within the non-AATD COPD group, $57 \%$ of the subjects were current smokers (Table 2).

All subjects provided verbal and written informed consent prior to participation in the study. The study was approved by the Human Research Protection Program at University of California, San Diego, and was conducted in manner consistent with the Declaration of Helsinki.

\section{Experimental design and exercise testing}

Each individual was studied over a two-day period. On the first day, subjects provided a small blood sample (5 ml via venipuncture) for assessment of hemoglobin concentration, genotyping and measurement of circulating AAT, and baseline concentration of serum for cytokines. Baseline assessment of venous cytokines were obtained on both testing days (Study day 1 and day 2) in order to evaluate what influence, if any, prior exercise testing may have on basal serum cytokines on the following day (i.e. second day of the study). Spirometry was used to assess airway obstruction using a Keystone dry-rolling seal spirometer (S\&M Instruments, Louisville, CO, USA).

Table 1 Anthropometric, medication and liver function data of subject groups

\begin{tabular}{|c|c|c|c|c|c|}
\hline & $A A T D+$ AUG $^{a}$ & $A A T D+$ AUG $^{b}$ & TD PFTnorm ${ }^{c}$ & non-AATD COPD ${ }^{d}$ & Healthy $^{\mathrm{e}}$ \\
\hline Lung health classification & COPD & COPD & Normal & COPD & Normal \\
\hline Genotype & $\mathrm{PiZZ}$ & PiZZ (PiSZ = 1) & PiZZ & PiMM & PiMM (PiMZ = 1) \\
\hline Number of subjects $(m, f)$ & $6(3,3)$ & $6(2,4)$ & $4(1,3)$ & $7(4,3)$ & $5(3,2)$ \\
\hline Age (years) & $56 \pm 4$ & $63 \pm 5$ & $55 \pm 5$ & $64 \pm 2$ & $56 \pm 1$ \\
\hline Height (cm) & $177 \pm 3$ & $170 \pm 4$ & $172 \pm 5$ & $167 \pm 4$ & $172 \pm 5$ \\
\hline Weight (kg) & $80 \pm 10$ & $83 \pm 13$ & $77 \pm 9$ & $82 \pm 8$ & $86 \pm 10$ \\
\hline DXA body fat (\%) & $32 \pm 4$ & $37 \pm 3$ & $33 \pm 7$ & $30 \pm 4$ & $32 \pm 5$ \\
\hline Lean body mass (kg) & $54 \pm 6$ & $52 \pm 8$ & $51 \pm 7$ & $57 \pm 5$ & $58 \pm 7$ \\
\hline Body mass Index $\left(\mathrm{kg} / \mathrm{m}^{2}\right)$ & $25 \pm 2$ & $28 \pm 3$ & $26 \pm 3$ & $29 \pm 2$ & $29 \pm 2$ \\
\hline Fat-free index $\left(\mathrm{kg} / \mathrm{m}^{2}\right)$ & $17 \pm 1$ & $18 \pm 2$ & $17 \pm 2$ & $20 \pm 1$ & $19 \pm 1$ \\
\hline Lean body mass (DXA) (kg) & $49 \pm 7$ & $51 \pm 7$ & $48 \pm 7$ & $53 \pm 5$ & $54 \pm 6$ \\
\hline Thigh mass (DXA) (kg) & $16 \pm 2$ & $13 \pm 2$ & $16 \pm 2$ & $15 \pm 1$ & $16 \pm 2$ \\
\hline \multicolumn{6}{|l|}{ Medication } \\
\hline No prescribed meds & $0 \%$ & $0 \%$ & $100 \%$ & $14 \%$ & $60 \%$ \\
\hline AAT Augmentation Therapy & $100 \%$ & $0 \%$ & $0 \%$ & $0 \%$ & $0 \%$ \\
\hline Bronchodilator & $100 \%$ & $100 \%$ & $0 \%$ & $86 \%$ & $0 \%$ \\
\hline Inhaled corticosteriods & $83 \%$ & $83 \%$ & $0 \%$ & $71 \%$ & $0 \%$ \\
\hline Oxygen & $33 \%$ & $0 \%$ & $0 \%$ & $29 \%$ & $0 \%$ \\
\hline Diuretics & $0 \%$ & $17 \%$ & $0 \%$ & $14 \%$ & $0 \%$ \\
\hline Anti-inflammatory & $0 \%$ & $0 \%$ & $0 \%$ & $0 \%$ & $0 \%$ \\
\hline Anti-depressive & $0 \%$ & $17 \%$ & $0 \%$ & $29 \%$ & $0 \%$ \\
\hline$\beta$-blockers & $33 \%$ & $33 \%$ & $0 \%$ & $29 \%$ & $40 \%$ \\
\hline \multicolumn{6}{|l|}{ Serum liver function tests } \\
\hline Total Bilirubin (mg/dL) & $0.48 \pm 0.06$ & $0.50 \pm 0.12$ & $0.45 \pm 0.09$ & $0.37 \pm 0.05$ & $0.51 \pm 0.12$ \\
\hline Albumin (g/dL) & $3.80 \pm 0.17$ & $3.45 \pm 0.15$ & $3.80 \pm 0.12$ & $3.77 \pm 0.11$ & $3.82 \pm 0.06$ \\
\hline Alanine Aminotransferase (U/L) & $42.3 \pm 15.2$ & $28.5 \pm 3.4$ & $41.0 \pm 12.7$ & $23.4 \pm 5.3$ & $30.6 \pm 2.9$ \\
\hline Serum AAT level (mg/dl) & $96 \pm 22^{b, c}$ & $<20 \pm 0^{\mathrm{a}, \mathrm{d}, \mathrm{e}}$ & $<20 \pm 0^{\mathrm{a}, \mathrm{d}, \mathrm{e}}$ & $113 \pm 11^{b, c}$ & $109 \pm 12^{b, c}$ \\
\hline
\end{tabular}

Data are mean \pm SE. AATD, alpha-1 antitrypsin deficient; AUG, augmentation therapy; PFTnorm, pulmonary function testing normal; AAT, alpha-1 antitrypsin; COPD, chornic obstructive pulmonary disease; DXA, dual-energy x-ray absorptiometry; $\mathrm{m}$, male; $\mathrm{f}$, female; Significance difference between group is denoted as follows, al different that AATD + AUG, 'b' different that AATD-AUG, ${ }^{\prime \prime \prime}$ different compared to AATD PDTnorm, 'd' different compared to COPD, 'e' different compared to Healthy. In all cases, significance is $p \leq 0.05$. 
Table 2 Pulmonary function, exercise capacity and smoking history of subject groups

\begin{tabular}{|c|c|c|c|c|c|}
\hline & $A A T D+A U G^{a}$ & AATD-AUG ${ }^{b}$ & AATD PFTnormc & non-AATD COPD ${ }^{d}$ & Healthy $^{\mathrm{e}}$ \\
\hline$\overline{F V C}$ (liters) & $3.85 \pm 0.42$ & $2.88 \pm 0.16^{c}$ & $4.27 \pm 0.64^{e}$ & $2.80 \pm 0.32^{c, e}$ & $3.96 \pm 0.57^{d}$ \\
\hline FVC (\% pred) & $88 \pm 6^{c}$ & $79 \pm 5^{c}$ & $109 \pm 6^{e}$ & $77 \pm 8^{\mathrm{cee}}$ & $95 \pm 6^{d}$ \\
\hline FEV1 (liters) & $1.23 \pm 0.25^{c, e}$ & $1.35 \pm 0.22^{\mathrm{c}, \mathrm{e}}$ & $3.22 \pm 0.47^{\mathrm{e}}$ & $1.49 \pm 0.11^{c, e}$ & $3.07 \pm 0.35^{d}$ \\
\hline FEV1 (\% pred) & $35 \pm 5^{c, e}$ & $47 \pm 7^{c, e}$ & $107 \pm 4^{e}$ & $54 \pm 7^{c, e}$ & $93 \pm 4^{d}$ \\
\hline FEV1/FVC & $31 \pm 3^{\mathrm{c}, \mathrm{d}, \mathrm{e}}$ & $47 \pm 7^{c, e}$ & $76 \pm 7^{\mathrm{c}, \mathrm{e}}$ & $56 \pm 4^{\mathrm{c}, \mathrm{e}}$ & $79 \pm 2^{d}$ \\
\hline FEV1/FVC (\% pred) & $40 \pm 4^{c, d, e}$ & $61 \pm 10^{c, e}$ & $97 \pm 2^{e}$ & $71 \pm 6^{c, e}$ & $99 \pm 3^{d}$ \\
\hline \multicolumn{6}{|c|}{ Bike (two-legs) exercise } \\
\hline Watts & $62 \pm 6^{\mathrm{ce} e}$ & $46 \pm 11^{c, e}$ & $176 \pm 47^{\mathrm{d}, \mathrm{e}}$ & $70 \pm 11^{\mathrm{c}, \mathrm{e}}$ & $126 \pm 17^{d}$ \\
\hline VO2peak (L/min) & $1.02 \pm 0.11^{c, e}$ & $0.69 \pm 0.13^{\mathrm{c}, \mathrm{e}}$ & $2.07 \pm 0.51^{d}$ & $1.16 \pm 0.12^{c, e}$ & $1.71 \pm 0.25^{d}$ \\
\hline VO2peak (ml/kg/min) & $12.6 \pm 0.5^{c}$ & $9.5 \pm 1.1^{c, e}$ & $26.9 \pm 5.6^{\mathrm{d}, \mathrm{e}}$ & $14.9 \pm 1.7^{c}$ & $20.3 \pm 3.3$ \\
\hline \multicolumn{6}{|c|}{ Knee extensor (single-leg) exercise } \\
\hline Watts & $25 \pm 3^{c}$ & $21 \pm 7^{c}$ & $59 \pm 23^{\mathrm{d}, \mathrm{e}}$ & $21 \pm 3^{c}$ & $26 \pm 1$ \\
\hline \multicolumn{6}{|l|}{ Smoking history } \\
\hline Never & $17 \%$ & $0 \%$ & $25 \%$ & $0 \%$ & $0 \%$ \\
\hline Ex-smoker & $83 \%$ & $100 \%$ & $75 \%$ & $43 \%$ & $100 \%$ \\
\hline Current & $0 \%$ & $0 \%$ & $0 \%$ & $57 \%$ & $0 \%$ \\
\hline
\end{tabular}

Data are mean \pm SE. AATD, alpha-1 antitrypsin deficient; AUG, augmentation therapy; PFTnorm, pulmonary function testing normal; AAT, alpha-1 antitrypsin; COPD, chronic obstructive pulmonary disease; FVC, forced vital capacity; FEV1, forced expiratory volume at 1 sec; VO2peak, peak oxygen consumption during exercise. Significance difference between group is denoted as follows, ${ }^{c \prime}$ different compared to AATD PFTnorm, ${ }^{\text {,d }}$ different compared to COPD, 'e' different compared to Healthy. No differences with respect to AATD + AUG ${ }^{\text {a' }}$ or AATD-AUG 'b' were found. In all cases, significance is $p \leq 0.05$.

Lean body mass was measured via dual-energy $\mathrm{x}$-ray absorpometry (DXA), and maximal exercise testing was performed using two different exercise modalities, 1) a single-leg knee-extensor exercise (KE), and 2) standard two-legged bicycle exercise. Use of the single-leg KE ergometer has been previously reported by us [37-39] and allows patients with cardiopulmonary disease to perform moderate- to high-intensity muscular work in the presences of limited pulmonary and/or cardiac reserve capacity allowing assessment of skeletal muscle responses to exercise which otherwise would be severely limited with whole body exercise. Further description of KE exercise and cycle ergometry are provided in Additional file 1.

On Study day 2, subjects had a muscle biopsy and blood sampling performed before and after KE exercise (60 min at $50 \%$ of maximal KE determine on day 1). Muscle biopsy from the vastus lateralis muscle (described in Additional file 1) prior to exercise was obtained from the non-exercising leg, while the muscle biopsy postexercise was obtained 4 hours after the single-leg KE exercise on the exercised leg. Prior to exercise, femoral venous catheter was inserted and secured in the leg to be exercised. Radial arterial catheter was placed in the non-dominant arm. Arterial and venous blood was obtained (in duplicate) at rest, after which samples were obtained at $10 \mathrm{~min}$ intervals during the 60 minute $\mathrm{KE}$ exercise, followed by blood draws at 30 minute intervals for up to 4-hours post exercise. The 4-hour time point was principally selected based on data demonstrating that peak muscle
IL-6 expression occurs between 4-8 hours post exercise [40]. Given that circulating expression of other cytokines (e.g. TNF $\alpha$ and IL-1 $\beta$ ) have also been shown to elevated between 1 and 24-hour post exercise [25,40] it was reasoned that examining muscle up to 4 hours post exercise would be an appropriate time to allow muscle levels to be altered.

\section{Blood sampling and handling}

Arterial and venous blood was collected using aseptic technique in serum separator vacutainer tubes (Kendall HealthCare Monoject; Fisher Scientific \#22029312) and allowed to clot at room temperature for 20 minutes. Thereafter, blood samples were centrifuged at 3,000 RPM (at 4 C) for 13 minutes. Serum was decanted, aliqouted and stored at $-80 \mathrm{C}$ until processed.

\section{Cytokine assessment}

For each cytokine, the venous blood from Study day 2 were compared against pre-exercise venous blood obtained on Study day 1 (screening day) to determine if maximal exercise testing from the previous day significantly altered baseline cytokine concentration on Study day 2. No significant differences in basal expression were observed between venous samples obtained on Study day 1 vs. day 2 (coefficient of variation $[\mathrm{CV}]$ for $\mathrm{IL}-1 \beta=0.55$, IL-6 $=0.50, \mathrm{TNF} \alpha=0.25, \mathrm{CRP}=0.29$ ), nor were differences found among the basal cytokine concentration between duplicate measures of either arterial (average 
CV for IL-1 $\beta=0.51$, IL-6 $=0.35, \mathrm{TNF} \alpha=0.22, \mathrm{CRP}=0.21$ ) or venous blood (average CV for IL- $1 \beta=0.30$, IL- $6=0.41$, $\mathrm{TNF} \alpha=0.21, \mathrm{CRP}=0.12$ ). Accordingly, the resting arterial and venous values were averaged to yield one resting arterial and venous serum values, respectively, which were used for all further statistical analyses. Additional description of the qualitative assessment of the methodology, variation, and minimal detection levels of the cytokine assays are provided in the Additional file 1: Methods.

\section{Statistical analyses}

Demographic, anthropomorphic, lung function and exercise data were compared across subjects groups using ANOVA with Fisher's PLSD post hoc testing when significant main effects were observed. Kruskal-Wallis test revealed cytokine data were not normally distributed across the subject groups, therefore cytokine data were square-root transformed and then analyzed using a 2-way mixed effect ANOVA model with repeated measures experimental design using either JMP/Pro V10 (SAS Inst. Inc., Cary, NC) or StatView Analysis (v5.0.01 SASS Inst. Inc., Cary NC). Post-hoc testing was performed when a significant overall $F$-ratio was achieved. Correlations were performed using a Spearman Rank Test. In all cases $p \leq 0.05$ was used to establish significance. All data shown are mean $\pm \mathrm{SE}$, unless otherwise indicated.

\section{Results}

\section{Subject characteristics}

Group data depicting demographic, anthropometric, and serum liver function tests are shown in Table 1. Spirometry data and maximal exercise performance are shown in Table 2. Supplemental tables are also provided to show spirometric comparison of the single MZ subject (Additional file 1: Table S1A) and the SZ subject (Additional file 1: Table S1B) compared to their respective groups. All subjects enrolled completed the study, however one subject (female in the healthy group) was eliminated from the analysis in the study when evidence of undiagnosed pulmonary abnormality was found (i.e. resting arterial $\mathrm{PO}_{2}=66$ Torr). Healthy subjects were well matched to all patients groups according to age, height and weight (Table 1).

As expected, all patients with COPD had reduced whole body aerobic capacity (i.e. VO2peak) compared to subjects with normal lung function (Table 2). While the healthy subjects had greater aerobic exercise capacity, single-leg knee extensor (KE) exercise capacity was not significantly different compared to COPD patients groups. Total body mass, body mass index (BMI), \% body fat and lean body mass were similar between healthy and all the COPD patients, which tends to support the idea that our 'healthy control group' subjects were similarly matched based on physical (in)activity.

\section{Subject group comparisons}

Resting serum cytokines were not different for any cytokine in venous blood obtained from Study Day 1 (measured prior to max testing) compared the following Day 2 (resting measured prior to exercise) indicating that previous day exercise activity had no influences on baseline cytokines concentration levels on the following day in our subjects (data not shown).

All measured cytokines displayed significant main effects according to subject groups, therefore post hoc testing for group differences were performed for each cytokine. Non-AATD COPD patients exhibited highest circulating concentrations for all cytokines measured (i.e. TNF $\alpha$, IL-1 $\beta, 1$ L-6 and CRP) in both arterial and venous blood compared to any subject group (Figures 1 and 2). Expression of all circulating cytokines were significantly greater in non-AATD COPD compared to healthy controls ( $\mathrm{p}<0.05$; Figures 1 and 2), except for venous IL-6 which was not significant ( $\mathrm{p}=0.099$; Figure 2) but displayed a similar trend.

In all cases, cytokine concentrations were lower in AATD COPD patients compared to COPD control patients (Figures 1 and 2). Arterial IL-1 $\beta$ and TNF $\alpha$ concentration were also observed to be lower in AATD + AUG patients than in healthy controls (Figure 1). Similarly, both arterial and venous TNFa levels were lower in AATD-AUG compared to healthy controls (Figure 2). In contrast, circulating arterial and venous CRP concentration were elevated in AATD + AUG and AATD-AUG patients compared to healthy controls and AATD PFTnorm, but were significantly lower compared to non-AATD COPD patients (Figures 1 and 2).

When comparing AATD COPD individuals 'on' versus 'off' augmentation therapy (AATD + AUG and AATD-AUG, respectively), we found no differences in the circulating levels of IL-6, IL-1 $\beta$ or CRP (Figures 1 and 2). However, venous TNF $\alpha$ was significantly greater in AATD + AUG compared to AATD-AUG (Figure 2).

\section{Circulating cytokine response to exercise}

Mixed effect ANOVA revealed no significant main effect for exercise (or subject group $\times$ exercise interaction) for any of the cytokines measured in arterial blood or venous blood. In addition, a separate mixed effect ANOVA that only included resting and exercise data (i.e. without post-exercise data) revealed no significant main effect for exercise for any of the cytokines measured. A summary depicting the group mean exercise data along with resting cytokine concentrations for both arterial and femoral venous blood is shown in Figure 3.

\section{Femoral venous-minus-arterial ( $\mathrm{v}-\mathrm{a})$ difference and skeletal muscle expression}

TNF $\alpha$ was the only cytokine showing significant ANOVA main effect for $\mathrm{v}$-a difference (ANOVA $\mathrm{p}<0.05$ ). Post hoc 


\section{Arterial}
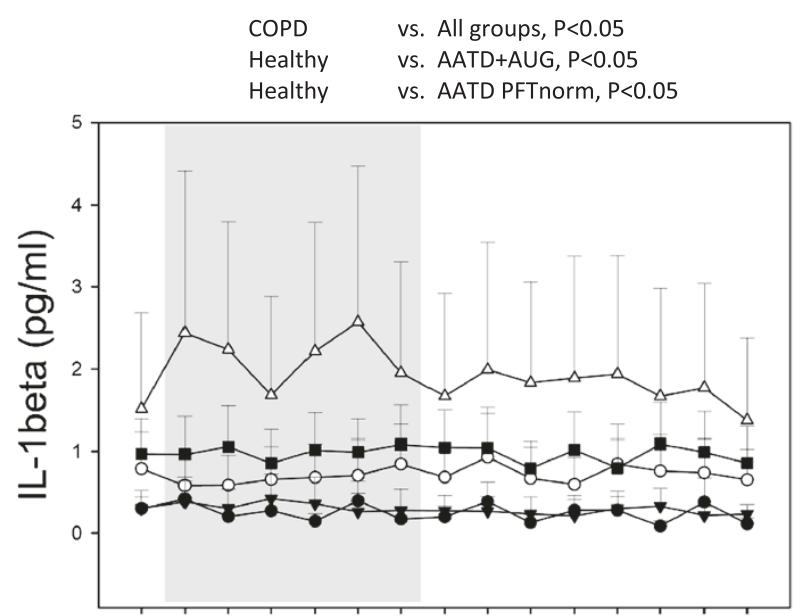

COPD

Healthy vs. AATD PFTnorm, $\mathrm{P}<0.05$

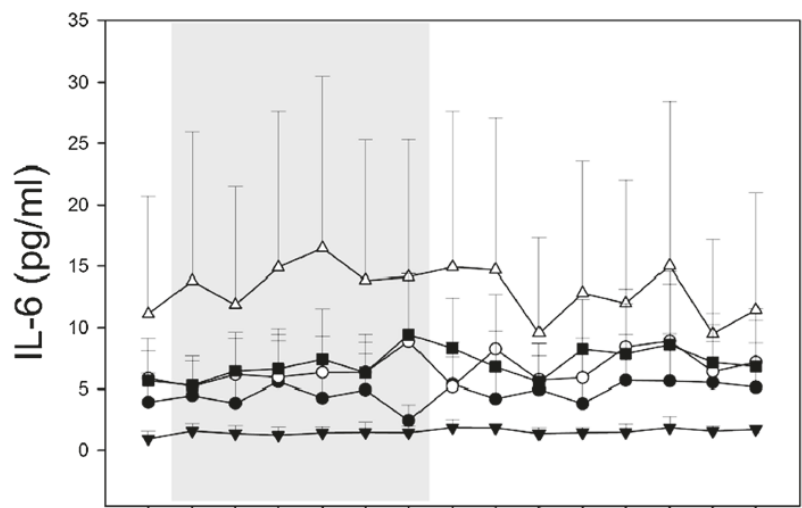

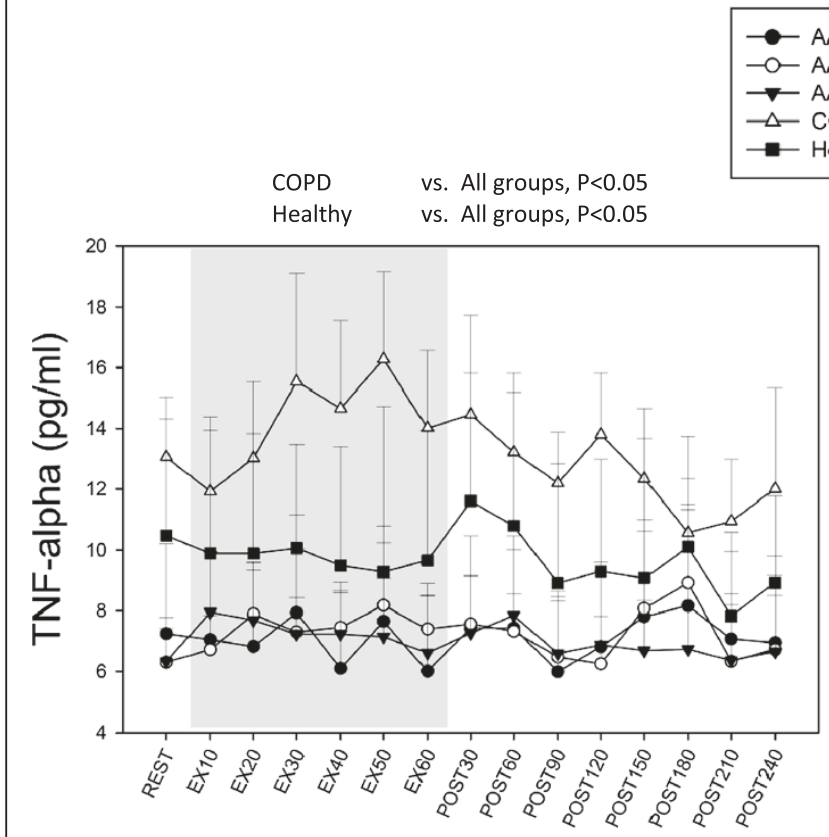

COPD vs. All groups, $\mathrm{P}<0.05$

Healthy vs. AATD+AUG, $P<0.05$

Healthy vs. AATD-AUG, $P<0.05$

AATD PFTnorm vs. AATD+AUG, $P<0.05$

AATD PFTnorm vs. AATD-AUG, $P<0.05$

Figure 1 Arterial serum levels of IL-1 $\beta$, IL-6, TNFa and CRP obtained under resting conditions (black bar), every 10 minutes during 1-hour single-leg knee extensor exercise at $50 \%$ of maximal exercise capacity (gray bars), and every 30 minutes (up to 4 hours) during recovery post exercise (white bars), in COPD individuals with alpha- 1 antitrypsin deficiency receiving augmentation therapy (AATD + AUG), AATD individuals not receiving augmentation therapy (AATD-AUG), AATD individuals with normal pulmonary function (AATD PFTnorm), non-AATD COPD patients (COPD), and age-/activity-matched controls with no lung disease (Healthy). Significant ANOVA main effect for group differences are shown above each graph. In all cases, significance is determined as $p<0.05$.

testing revealed TNF $\alpha$-a difference was greater in AATD + AUG compared to AATD-AUG and COPD control groups $(p<0.05)$, along with similar tendency for Healthy subjects $(\mathrm{p}=0.0516)$ (Figure 4).

In skeletal muscle, only TNF $\alpha$ was found to exhibit a significant ANOVA main effect (Figure 5). Skeletal muscle TNF $\alpha$ was greater in AATD-AUG subject compared to all other groups (Figure 5). Skeletal muscle expression for IL-1 $\beta$ was below the minimal detectable level of our assay (i.e. $0.08 \mathrm{pg} / \mathrm{mL}$ ) and therefore unable to be determined.

Exercise exerted no significant effect on the skeletal muscle concentration of any cytokines measured (Figure 5).

\section{Correlation of circulating cytokines to airway obstruction}

In AATD COPD patients (i.e. AATD + AUG and AATDAUG groups) we find no evidence to support a correlation between circulating arterial cytokines and the degree of 


\section{Femoral Venous}

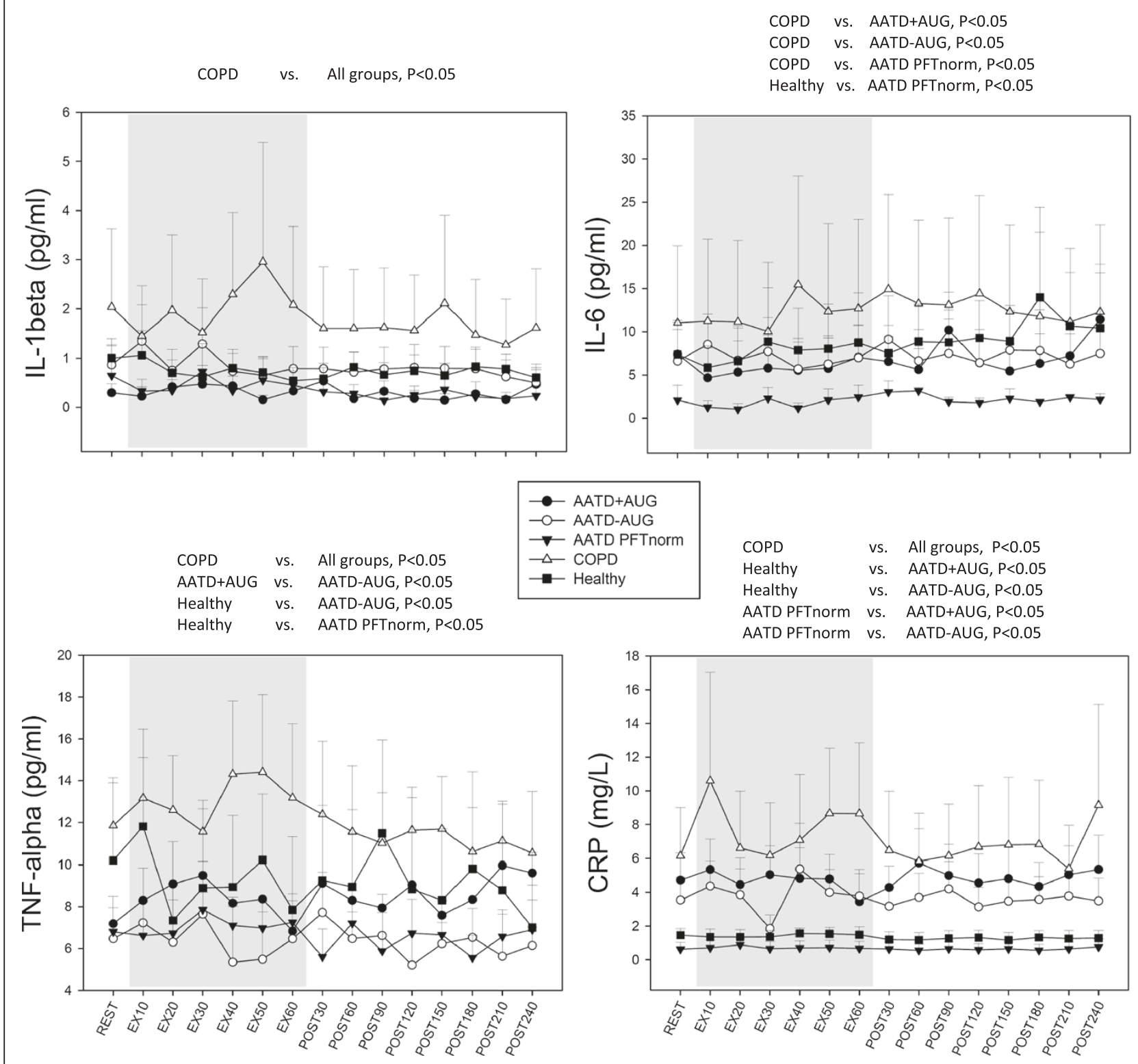

Figure 2 Femoral venous serum levels of cytokines from same conditions and subject groups in Figure 1. Significant ANOVA main effect for group differences are shown above each graph. In all cases, significance is determined as $p<0.05$.

airway obstruction (Figure 6). In nonAATD COPD patients, there was a trend for increasing TNF $\alpha(p=0.09)$, IL-1 $\beta(p=0.57)$ and IL-6 $(\mathrm{p}=0.16)$ in association with worsening FEV1/FVC, but no significant correlation was observed (Figure 6).

\section{Discussion}

The main findings of this study are, 1) AATD patients with COPD have lower circulating cytokines concentration compared to non-AATD COPD patients, 2) patients with
AATD COPD receiving augmentation therapy have lower TNF $\alpha$ expression in skeletal muscle and a greater venousminus-arterial difference for circulating TNF $\alpha$ (suggesting net efflux of TNF $\alpha$ from the skeletal muscle) compared to AATD COPD patients not receiving augmentation therapy, and 3) 60-minutes of sustained moderate-intensity exercise had no significant effect for any of the measured cytokines. These changes were seen reproducibly across sequential arterial and venous blood samples within individual subjects and across patient subject groups. 


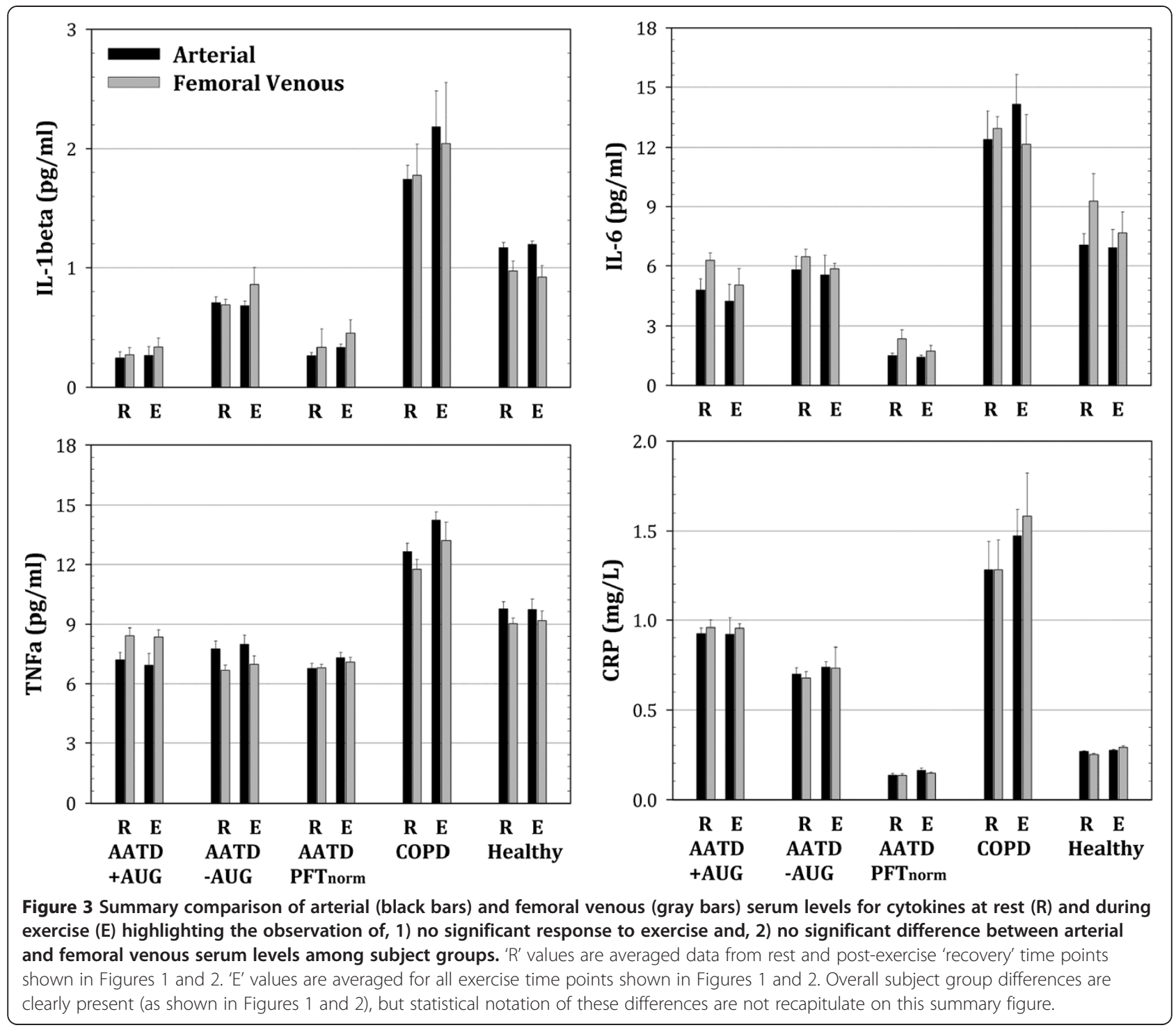

Systemic inflammation in AATD and non-AATD COPD

Large scale cross-sectional studies have documented the association between systemic inflammation and reduced lung function in patients with COPD [41] as well as in healthy subjects [42]. Our data, showing elevated circulating concentrations of IL- $1 \beta$, IL-6, TNF $\alpha$ and CRP are consistent with both clinical and laboratory evidence showing increased chronic systemic inflammation in COPD. More importantly, our data show that this finding cannot be generalized to patients with COPD resulting from AATD. In all cases, cytokine concentration was lower in AATD individuals (with or without lung disease) compared to the non-AATD COPD patients (Figures 1 and 2). When compared to healthy control subjects, only CRP was elevated in AATD COPD patients, but this increase was still lower compared to CRP in non-AATD COPD patients (Figures 1, 2 and 3).
The elevated CRP concentration seen in our AATD subjects with COPD may lend support to the idea that polymers from abnormal variants of $\alpha_{1}$-antitrypsin alleles are pro-inflammatory [43-45]. However, since AATD individuals with normal spirometry (AATD PFTnorm $_{\text {) }}$ did not have elevated CRP, and yet exhibit a similar low circulating AAT as AATD-AUG with COPD (Table 1), it seems more likely the elevated CRP is associated with the pathophysiology of the COPD sequelae rather than a response to polymers associated with $\alpha_{1}$-antitrypsin allele variants. It is surprising, however, that AATD COPD patients had lower blood levels of CRP (compared to non-AATD COPD patients, Figures 1, 2 and 3) but yet exhibited similar, if not greater, airway obstruction (Table 1). Based on the existing literature [46,47], it might have been expected that individuals with the worst lung function would have the greatest increases in circulating CRP. 

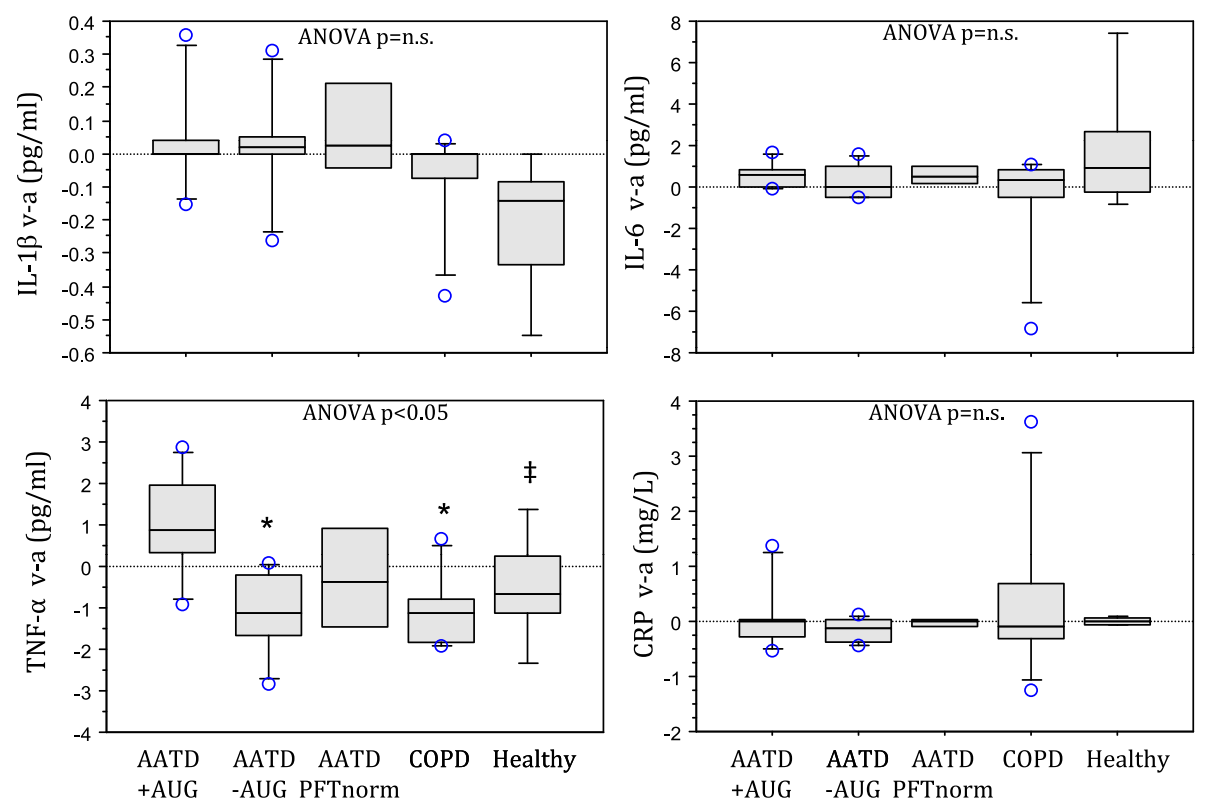

Figure 4 Box plot showing femoral venous-minus-arterial $(v-a)$ cytokine values obtained from mean venous and arterial data represented for groups in Figures 1 and 2 . Venous values are obtained from the femoral vein, therefore $v-a>0$ imply muscle efflux of cytokines, whereas $v$ - $a<0$ imply muscle uptake. Zero v-a values imply no muscle involvement. Box boundaries show 25th and 75th percentile, while whisker bars represent 10th and 90th percentile. All observations $>90$ th percentile are individually represented as open circle (o) data point. Group median is shown as center line within the box. Post-hoc testing was only performed on TNF-a, where a significant ANOVA main effect $(p<0.05)$ was observed. * indicates $p<0.05$ compared to AATD + AUG, $\neq p=0.0516$ compared to AATD + AUG.

One explanation may be that plasma CRP is produced principally in hepatocytes and individuals with AATD (in addition to developing emphysema) can also develop cirrhosis of the liver, potentially leading to liver failure as a result of excess deposition of abnormal $\alpha_{1}$-antitrypsin protein in the liver. But we found no evidence of liver dysfunction in any of AATD subjects (Table 1). There are only few small studies that have evaluated the risk of cardiovascular events in AATD individuals [48-50]. Despite conflicting results [51], there is evidence of altered vessel elasticity (e.g. increased aortic wall stiffness) that supports elevated risk of cardiovascular disease [49,50], as well as occult musculoskeletal changes [48], both of which could contribute to the morbidity and mortality in AATD individuals. Although the severity of pulmonary dysfunction appears worse in AATD patients with COPD (compared to non-AATD COPD patients), circulating biomarkers for inflammatory cytokines (other than CRP) in AATD COPD patients were similar to healthy subjects. These data highlight the fact that it cannot be assumed that the inflammatory sequelae for COPD are similar between AATD and non-AATD COPD patients. Indeed, while non-AATD COPD patients are often found to have elevated circulating TNF $\alpha$ concentration [see meta-analysis review, Ref [41]], as seen in our data (Figures 1 and 2), we find no significant evidence of elevated circulating TNF $\alpha$ in AATD COPD individuals - even with greater degree of airway obstruction (Figure 6). Previous studies examining inflammatory biomarkers in PiZZ COPD patients report similar observations $[9,52]$. Collectively, these data oppose the idea that systemic inflammation contributes to the underlying lung pathology in patients with AATD COPD, as AATD COPD individuals with the greatest deficits in lung function exhibited minimal evidence of systemic inflammation. These data also add to the recognition that while the clinical manifestations of COPD are often very similar, the underlying mechanism and pathology are much less easily defined or even homogeneous in nature. It is important for future COPD research to evaluate the origins of the heterogeneity observed in patients with COPD before we can better understand how best to treat and individually manage patients suffering from COPD.

\section{Effect of augmentation therapy on inflammatory cytokines}

In general we found no significant differences between AATD patients with COPD receiving augmentation therapy (AATD + AUG) compared to those not receiving augmentation therapy (AATD-AUG). However, it was observed that AATD + AUG patients had slightly greater circulating TNF $\alpha$ in venous blood compared to AATD-AUG patients (Figure 2). A significant difference in circulating TNF $\alpha$ 

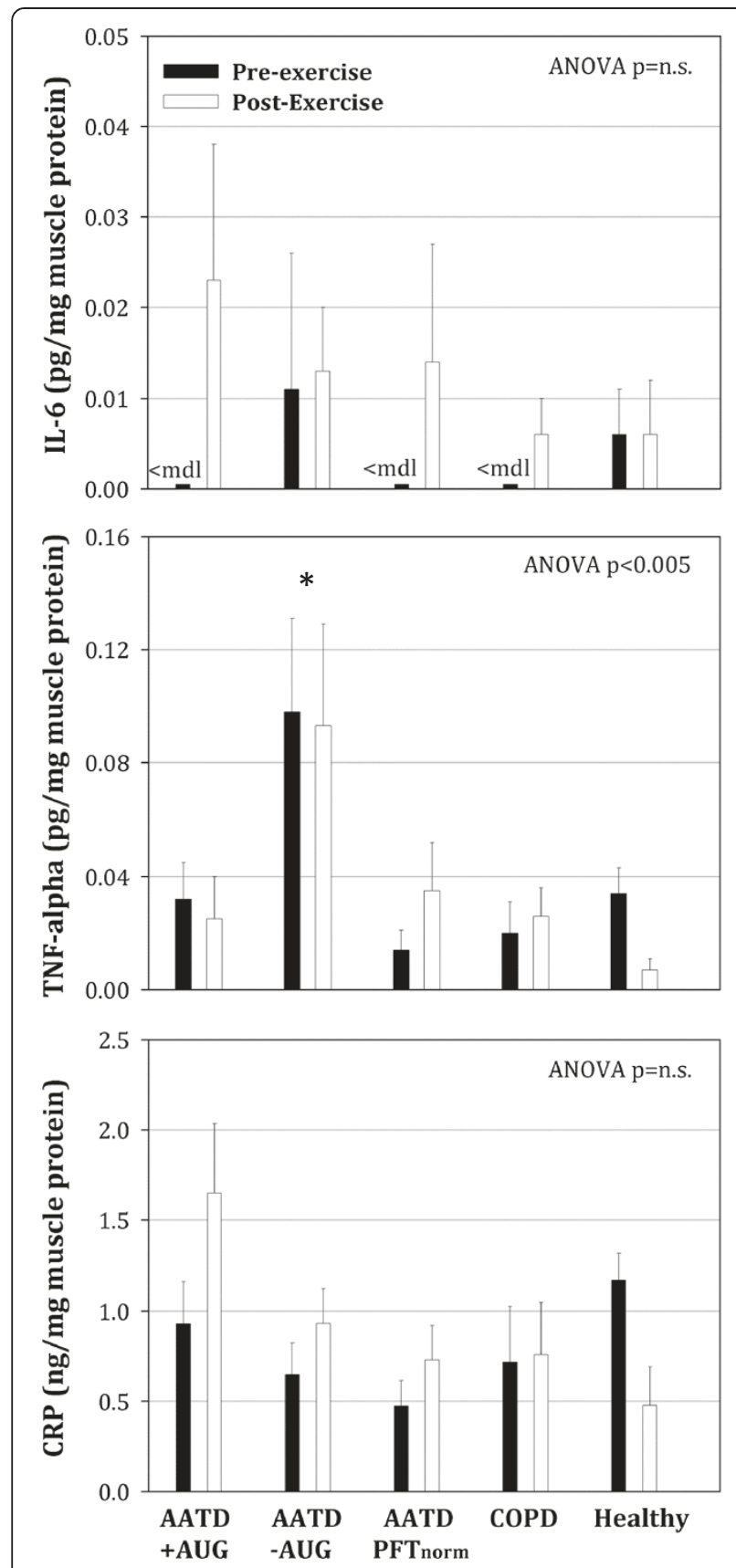

Figure 5 Skeletal muscle cytokine expression (normalized to total muscle protein) from muscle biopsies of vastus lateralis muscle before and after the 60-minutes of single-leg exercise. Pre-exercise biopsy was obtained on non-exercising leg prior to exercise, while post-exercise biopsy was obtained 4-hours post-exercise on the exercising leg. We provide indication where detection of cytokines fell below the minimal detectable limit $(<\mathrm{mdl})$ of the assay, i.e. all samples for $\mathrm{IL}-1 \mathrm{~b}$ (therefore no data shown) and for some samples in IL-6. Post-hoc testing was only performed on TNFa, where a significant ANOVA main effect $(p<0.005)$ was observed. No significant main effect was observed for IL-6, therefore post-hoc testing between groups was not performed. * indicates $p<0.05$ compared to all other groups. between these groups was also seen when calculating the venous-minus-arterial difference in TNF $\alpha$ (Figure 4). The latter finding (i.e. positive TNF $\alpha \mathrm{v}$-a difference due to greater femoral venous versus arterial concentration) suggests that there is net outflow or 'spillover' of TNF $\alpha$ into the circulation from skeletal muscle in AATD + AUG patients. In contrast, the negative TNF $\alpha$ $\mathrm{v}$-a values (i.e. higher arterial versus femoral venous concentrations) seen in AATD-AUG subjects (Figure 4), suggests a net muscle uptake of TNF $\alpha$ in these subjects. This finding is supported by elevated TNF $\alpha$ expression in skeletal muscle of AATD-AUG subjects that is not seen in AATD + AUG subjects (Figure 5). However, the interpretation of this finding still remains somewhat ambiguous, given that similar negative TNF $(\mathrm{v}-\mathrm{a})$ values were seen in the control groups (i.e. AATD PFTnorm, $_{\text {, }}$ non-AATD COPD, and Healthy), yet only AATD-AUG subjects exhibited elevated skeletal muscle TNFa.

CRP was the only other cytokine found to be greater in AATD patients with COPD compared to controls (as previously discussed). But for CRP there was no difference between AATD individuals 'on' or 'off' augmentation therapy, suggesting that AAT replacement therapy had no effect on circulating CRP concentration. Taken together, it remains uncertain what clinical effect, if any, that differences in circulating TNF $\alpha$ and CRP may actually exert between AATD patients 'on' versus 'off' augmentation therapy.

\section{Inflammatory response in skeletal muscle}

Several studies have reported on the cytokine responses in skeletal muscle of COPD patients. [53-55], but to our knowledge no studies have examined skeletal muscle in AATD individuals or what effect augmentation therapy may have. Our data suggest that there is elevated TNF $\alpha$ in the skeletal muscle of AATD-AUG subjects (Figure 5), which, to some extent, supports the implication of an active musculoskeletal inflammatory process. But, as previously mentioned for circulating cytokines, the importance of this finding remains somewhat unclear in muscle, since 1) increases in other proinflammatory cytokines were not observed in the skeletal muscle of this patient group, and 2) a similar increase in muscle TNF $\alpha$ was not also observed in the non-AATD COPD patient group who also had evidence of elevated systemic inflammation. But, whether or not TNF $\alpha$ is typically elevated in skeletal muscle of patients with COPD remains controversial. While some studies report elevated muscle TNF $\alpha$ expression $[28,54]$, others show no change [56,57] or decreased TNF $\alpha$ [53]. These discrepancies might be explained by heterogeneity in patient population (as we show), by differences in study design, and/or in the sensitivity of the assay(s) that are used to measure TNF $\alpha$. 

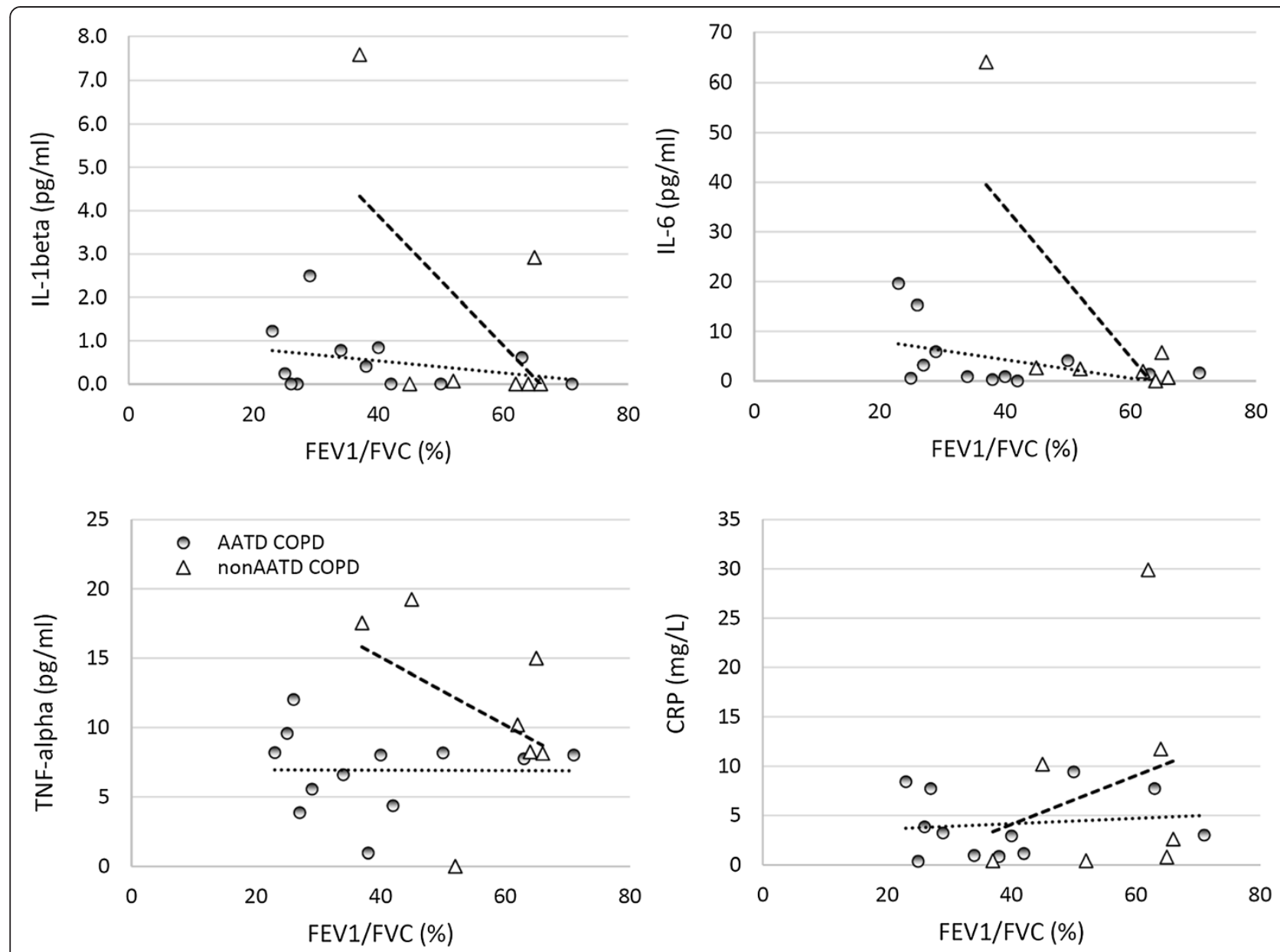

Figure 6 Correlation between circulating arterial cytokines and airway obstruction for AATD COPD patients (i.e. AATD + AUG and AATD-AUG groups shown as shaded circles) and for non-AATD COPD patients (open triangles). Dotted regression line reflect data for AATD COPD, whereas dashed regression line reflect data for non-AATD COPD.

\section{Exercise and inflammation}

In healthy individuals, strenuous exercise elicits an acute phase inflammatory response that is rapidly counter-balanced by anti-inflammatory cytokines [25]. This acute phasic response is actually beneficial and helps to maintain a strong and healthy immune system. But there has been concern that habitual exercise in COPD patients may superimpose an added inflammatory burden that may prove more harmful than good [58]. Our data, using moderate-intensity exercise (for 1-hour) at approximately $50 \%$ of individual's maximal aerobic power, finds no evidence of exercise-induced inflammatory stress in either AATD patients (with no underlying systemic inflammation) or non-AATD COPD patients (which had evidence of chronic systemic inflammation). This is consistent with other data reporting acute inflammatory responses to exercise in patients with COPD [59], and more generally with large-scale epidemiologic studies that have repeatedly established the benefits of exercise in maintaining health and longevity. Indeed, exercise capacity is touted to be the best predictor of an AATD individual's health status (better than high-resolution computed tomography or lung function assessments) [60], and our data finds no evidence to suggest that exercise activates or exacerbates either acute or chronic inflammatory pathways in either AATD or non-AATD COPD patients. To the contrary, AATD individuals with normal spirometry had far greater functional exercise capacity (seen with both cycle ergometry and KE exercise, Table 1), which could suggest that maintaining one's aerobic capacity may be protective for COPD progression. However, based on our study design, we cannot know whether aerobic exercise is truly protective for disease progression, or if this observation is simply a coincidence based on the small subset of the individuals in our study.

\section{Study limitations}

When making cross-sectional group comparisons, it must be recognized that our relatively small subject population ( $n=4-7$ subjects per group) combined with 
multiple comparisons could increase the potential of identifying spurious relationships. But, our study also included a repeated measure study design, in which each subject served at their own control. Indeed, from each subject we obtained 34 temporally independent blood measurements (17 arterial, 17 femoral venous) and 2 muscle biopsy measurements (one pre-exercise and one post-exercise). Given the number of individual measurements made in each subject, the statistical power for the repeated measures relating to exercise response is high (i.e. $\beta>0.95$ ). Based on the large number of individual blood measurements made, we also have a high degree of confidence in the individual mean values obtained for each subject. While this does not eliminate the concern for variability among small total number of subjects within each group (i.e. the cross-group comparisons), there is greater confidence in the accuracy of the absolute mean values for each subject that helps to increase confidence in the interpretation of the cross-sectional data. For example, comparing variability in Figures 1 and 2 (which report individual rest and exercise data points) to Figure 3 data (which reports a summary of mean values for rest and exercise data, respectively) it is clear the lower variability evident in Figure 3 provides greater confidence in the evaluating across patient groups differences that are mirrored in Figures 1 and 2. Nonetheless, it must be stated, given the small number of patients in each group, any cross-sectional interpretation must be view with caution.

\section{Conclusion}

These data establish that AATD patients with COPD do not experience the same inflammatory cytokine response as that typically seen in non-AATD COPD patients. However, it is evident the circulating the CRP (albeit lower compared to that seen in non-AATD COPD patients) is elevated in AATD COPD patients compared to controls subjects with normal lung function. In general, augmentation therapy did not appear to alter circulating cytokine concentrations, except for TNF $\alpha$. AATD COPD patients on augmentation therapy exhibited a positive venous-minus-arterial TNF $\alpha$ serum difference, whereas those off augmentation therapy exhibited a negative venous-minus-arterial TNF $\alpha$ difference. This negative v-a difference (suggesting muscle sequestration of TNF $\alpha$ ) in AATD COPD subjects not receiving augmentation therapy correlated with significantly higher muscle concentration of TNF $\alpha$ compared to patients on augmentation therapy. While these data cannot establish a cause-andeffect relationship, they suggest that patients receiving augmentation therapy may have net efflux of TNFa from the skeletal muscle. Lastly, our data indicate that exercising for 60 minutes at $50 \%$ of maximal work capacity does not significantly increase expression of circulating inflammatory cytokines. Collectively, these data suggest that systemic inflammation is not simply a "spill over" function of pathophysiology associated with destruction of lung tissue per se, but rather suggests that compounds or mechanism(s) associated with environmental risk factors (such as tobacco smoke) likely play a principle role in eliciting the inflammation reaction.

\section{Additional file}

Additional file 1: Supplemental Material.

\section{Competing interests}

Funding for this project was supported by an unrestricted grant from CSL Behring. Support was also provided by the UCSD General Clinical Research Center in conducting DXA scanning. Dr. Olfert received funding support from American Heart Association (10BGIA3630002), UCSD National Skeletal Muscle Research Group (NIH R24HD050837), West Virginia University School of Medicine and West Virginia Clinical and Translational Science Institute (NIH/NIGMS U54GM104942). Support for Drs. Wagner and Malek were provided NIH grant P01 HL17731-28. Funding for WVU Core Facilities used for cytokine analyses was provided by NIH grants P30 GM103488 and P30 RR032138.

None of the authors have any personal financial support or involvement with CSL Behring. Study support from CSL Behring did not influence study design, data collection, analysis or interpretation, writing of the manuscript or decision to submit for publication.

\section{Authors' contributions}

IMO and PDW conceived of the study design and were involved in all aspects for the study (i.e. patient recruitment, data collection, analysis, and manuscript preparation). MHM, TMLE and HW were involved in providing intellectual content, data collection, data analysis, and drafting/editing the manuscript. All authors read and approved the final manuscript.

\section{Acknowledgements}

The authors wish to especially thank all the study subjects for their time and commitment in participating in the study, without them this study would not have been possible. We also wish to express our gratitude to the Alpha-1 Foundation, Dr. Charlie Strange (Medical Director, Alpha-1 Foundation Database, University of South Carolina), and Dr. Joe Ramsdell (Medical Director) and Paul Ferguson, RRT, RCP (Director) of the UCSD Clinical Trials Center for their support in helping to recruit patients for this study. In addition we are grateful for the technical assistance provided by Jeff Struthers, Darryl Neusome, Dr. Amy Knapp, and Dr. Courtney Henderson in data collection (at UCSD); Janelle Stricker for anaylses of the cytokines (WV School of Medicine); and Dr. Danyel Tacker (WU Clinical Laboratory) for liver function analysis.

\section{Author details}

${ }^{1}$ Center for Cardiovascular and Respiratory Sciences, Division of Exercise Physiology, One Medical Center Dr, West Virginia University School of Medicine, Morgantown, WV 26506-9105, USA. ${ }^{2}$ Integrative Physiology of Exercise Laboratory, Eugene Applebaum College of Pharmacy \& Health Sciences, Wayne State University, 259 Mack Avenue, Detroit, MI 48201, USA. ${ }^{3}$ Department of Medicine, Division of Physiology, University of California, San Diego, 9500 Gilman Drive, La Jolla, CA 92093-0623, USA. ${ }^{4}$ Department of Thoracic Medicine, Haukeland University Hospital, Jonas Lies vei 65, N-5021 Bergen, Norway.

Received: 30 December 2013 Accepted: 19 June 2014 Published: 30 June 2014

\section{References}

1. Laurell CB, Eriksson S: The electrophoretic alpha-1-globulin pattern of serum in alpha-1-antitrypsin deficiency. Scand J Clin Lab Invest 1963, 15:132-140.

2. Tobin MJ, Cook PJ, Hutchison DC: Alpha 1 antitrypsin deficiency: the clinical and physiological features of pulmonary emphysema in subjects 
homozygous for Pi type Z. A survey by the British Thoracic Association. Br J Dis Chest 1983, 77(1):14-27.

3. Wood AM, Harrison RM, Semple S, Ayres JG, Stockley RA: Outdoor air pollution is associated with rapid decline of lung function in alpha-1antitrypsin deficiency. Occup Environ Med 2010, 67(8):556-561.

4. Wood AM, De Pablo P, Buckley CD, Ahmad A, Stockley RA: Smoke exposure as a determinant of autoantibody titre in alpha(1)-antitrypsin deficiency and COPD. Eur Respir J 2011, 37(1):32-38.

5. Di Stefano A, Capelli A, Lusuardi M, Balbo P, Vecchio C, Maestrelli P, Mapp CE, Fabbri LM, Donner CF, Saetta M: Severity of airflow limitation is associated with severity of airway inflammation in smokers. Am J Respir Crit Care Med 1998, 158(4):1277-1285.

6. De Godoy I, Donahoe M, Calhoun WJ, Mancino J, Rogers RM: Elevated TNF-alpha production by peripheral blood monocytes of weight-losing COPD patients. Am J Respir Crit Care Med 1996, 153(2):633-637.

7. Fabbri LM, Rabe KF: From COPD to chronic systemic inflammatory syndrome? Lancet 2007, 370(9589):797-799.

8. Sinden NJ, Stockley RA: Systemic inflammation and comorbidity in COPD: a result of 'overspill' of inflammatory mediators from the lungs? Review of the evidence. Thorax 2010, 65(10):930-936.

9. Aldonyte R, Jansson L, Piitulainen E, Janciauskiene S: Circulating monocytes from healthy individuals and COPD patients. Respir Res 2003, 4:11.

10. Agusti AG, Noguera A, Sauleda J, Sala E, Pons J, Busquets X: Systemic effects of chronic obstructive pulmonary disease. Eur Respir J 2003, 21(2):347-360

11. Schols AM, Buurman WA, van den Brekel AJ S, Dentener MA, Wouters EF: Evidence for a relation between metabolic derangements and increased levels of inflammatory mediators in a subgroup of patients with chronic obstructive pulmonary disease. Thorax 1996, 51(8):819-824.

12. Elliott $P R$, Bilton $D$, Lomas DA: Lung polymers in $Z$ alpha1-antitrypsin deficiency-related emphysema. Am J Respir Cell Mol Biol 1998, 18(5):670-674.

13. Mulgrew AT, Taggart CC, Lawless MW, Greene CM, Brantly ML, O'Neill SJ, McElvaney NG: Z alpha1-antitrypsin polymerizes in the lung and acts as a neutrophil chemoattractant. Chest 2004, 125(5):1952-1957.

14. Wang Y, He Y, Abraham B, Rouhani FN, Brantly ML, Scott DE, Reed JL: Cytosolic, autocrine alpha-1 proteinase inhibitor (A1PI) inhibits caspase-1 and blocks IL-1 beta dependent cytokine release in monocytes. PLOS One 2012, 7(11):e51078

15. Malerba M, Ricciardolo F, Radaeli A, Torregiani C, Ceriani L, Mori E, Bontempelli M, Tantucci C, Grassi V: Neutrophilic inflammation and IL-8 levels in induced sputum of alpha-1-antitrypsin PiMZ subjects. Thorax 2006, 61(2):129-133.

16. Stone H, McNab G, Wood AM, Stockley RA, Sapey E: Variability of sputum inflammatory mediators in COPD and alpha1-antitrypsin deficiency. Eur Respir J 2012, 40(3):561-569.

17. Pott GB, Chan ED, Dinarello CA, Shapiro L: Alpha-1-antitrypsin is an endogenous inhibitor of proinflammatory cytokine production in whole blood. J Leukoc Biol 2009, 85(5):886-895

18. Churg A, Wang X, Wang RD, Meixner SC, Pryzdial ELG, Wright JL: a1-Antitrypsin Suppresses TNF- $a$ and MMP-12 Production by Cigarette Smoke-Stimulated Macrophages. Am J Respir Cell Mol Biol 2007, 37(2):144-151.

19. Stockley RA, Bayley DL, Unsal I, Dowson L: The Effect of Augmentation Therapy on Bronchial Inflammation in a1-Antitrypsin Deficiency. Am J Respir Crit Care Med 2002, 165(11):1494-1498.

20. Jonigk D, Al-Omari M, Maegel L, Müller M, Izykowski N, Hong J, Hong K, Kim S-H, Dorsch M, Mahadeva R, Laenger F, Kreipe H, Braun A, Shahaf G, Lewis EC, Welte T, Dinarell CA, Janciauskiene S: Anti-inflammatory and immunomodulatory properties of a1-antitrypsin without inhibition of elastase. Proc Natl Acad Sci 2013, 110(37):15007-15012.

21. Collins $C B$, Aherne CM, Ehrentraut SF, Gerich ME, McNamee EN, McManus MC, Lebsack MDP, Jedlicka P, Azam T, De Zoeten EF, Dinarello CA, Rivera-Nieves J: Alpha-1-antitrypsin Therapy Ameliorates Acute Colitis and Chronic Murine Ileitis. Inflamm Bowel Dis 2013, 19(9):1964-1973.

22. Schmid ST, Koepke J, Dresel M, Hattesohl A, Frenzel E, Perez J, Lomas DA, Miranda E, Greulich T, Noeske S, Wencker M, Teschler H, Vogelmeier C, Janciauskiene S, Koczulla AR: The effects of weekly augmentation therapy in patients with PiZZ alpha1-antitrypsin deficiency. Int J Chron Obstruct Pulmon Dis 2012, 7:687-696.

23. Lieberman J: Augmentation therapy reduces frequency of lung infections in antitrypsin deficiency: a new hypothesis with supporting data. Chest 2000, 118(5):1480-1485.
24. Pedersen BK, Hoffman-Goetz L: Exercise and the immune system: regulation, integration, and adaptation. Physiol Rev 2000, 80(3):1055-1081.

25. Ostrowski K, Rohde T, Asp S, Schjerling P, Pedersen BK: Pro- and anti-inflammatory cytokine balance in strenuous exercise in humans. J Physiol 1999, 515(Pt 1):287-291.

26. Petersen AM, Pedersen BK: The anti-inflammatory effect of exercise. J Appl Physiol 2005, 98(4):1154-1162.

27. Petersen $\mathrm{AM}$, Pedersen $\mathrm{BK}$ : The role of $\mathrm{IL}-6$ in mediating the anti-inflammatory effects of exercise. J Physiol Pharmacol 2006, 57(Suppl 10):43-51.

28. Rabinovich RA, Figueras M, Ardite E, Carbo N, Troosters T, Filella X, Barbera JA, Fernandez-Checa JC, Argiles JM, Roca J: Increased tumour necrosis factor-alpha plasma levels during moderate-intensity exercise in COPD patients. Eur Respir J 2003, 21(5):789-794.

29. Van Helvoort HA, Heijdra YF, Thijs HM, Vina J, Wanten GJ, Dekhuiizen PN: Exercise-induced systemic effects in muscle-wasted patients with COPD. Med Sci Sports Exerc 2006, 38(9):1543-1552.

30. Van Helvoort HA, van de Pol MH, Heijdra YF, Dekhuijzen PN: Systemic inflammatory response to exhaustive exercise in patients with chronic obstructive pulmonary disease. Respir Med 2005, 99(12):1555-1567.

31. Van Helvoort HA, Heijdra YF, De Boer RC, Swinkels A, Thijs HM, Dekhuijzen PN: Six-minute walking-induced systemic inflammation and oxidative stress in muscle-wasted COPD patients. Chest 2007, 131(2):439-445.

32. Spruit MA, Troosters T, Gosselink R, Kasran A, Decramer M: Acute inflammatory and anabolic systemic responses to peak and constant-work-rate exercise bout in hospitalized patients with COPD. Int J Chron Obstruct Pulmon Dis 2007, 2(4):575-583

33. Canavan J, Garrod R, Marshall J, Jackson D, Ansley P, Jewell A: Measurement of the acute inflammatory response to walking exercise in COPD: effects of pulmonary rehabilitation. Int J Chron Obstruct Pulmon Dis 2007, 2(3):347-353.

34. Garrod R, Ansley P, Canavan J, Jewell A: Exercise and the inflammatory response in chronic obstructive pulmonary disease (COPD)-Does training confer anti-inflammatory properties in COPD? Med Hypotheses 2007, 68(2):291-298.

35. Vogiatzis I, Stratakos G, Simoes DC, Terzis G, Georgiadou O, Roussos C, Zakynthinos S: Effects of rehabilitative exercise on peripheral muscle TNFalpha, IL-6, IGF-I and MyoD expression in patients with COPD. Thorax 2007, 62(11):950-956.

36. Davidson WJ, Verity WS, Traves SL, Leigh R, Ford GT, Eves ND: Effect of incremental exercise on airway and systemic inflammation in patients with COPD. J Appl Physiol 2012, 112(12):2049-2056.

37. Richardson R, Leek B, Gavin T, Haseler L, Mudaliar S, Henry R, Mathieu-Costello O, Wagner P: Reduced mechanical efficiency in chronic obstructive pulmonary disease but normal peak VO2 with small muscle mass exercise. Am J Respir Crit Care Med 2004, 169:89-96.

38. Esposito F, Mathieu-Costello O, Shabetai R, Wagner PD, Richardson RS: Limited maximal exercise capacity in patients with chronic heart failure: partitioning the contributors. J Am Coll Cardiol 2010, 55(18):1945-1954.

39. Esposito F, Reese V, Shabetai R, Wagner PD, Richardson RS: Isolated quadriceps training increases maximal exercise capacity in chronic heart failure: the role of skeletal muscle convective and diffusive oxygen transport. J Am Coll Cardiol 2011, 58(13):1353-1362.

40. Louis E, Raue U, Yang Y, Jemiolo B, Trappe S: Time course of proteolytic, cytokine, and myostatin gene expression after acute exercise in human skeletal muscle. J Appl Physiol 2007, 103(5):1744-1751.

41. Gan WQ, Man SF, Senthilselvan A, Sin DD: Association between chronic obstructive pulmonary disease and systemic inflammation: a systematic review and a meta-analysis. Thorax 2004, 59(7):574-580.

42. Hancox RJ, Poulton R, Greene JM, Filsell S, McLachlan CR, Rasmussen F, Taylor DR, Williams MJ, Williamson A, Sears MR: Systemic inflammation and lung function in young adults. Thorax 2007, 62(12):1064-1068.

43. Alam S, Li Z, Janciauskiene S, Mahadeva R: Oxidation of $Z$ alpha1-antitrypsin by cigarette smoke induces polymerization: a novel mechanism of early-onset emphysema. Am J Respir Cell Mol Biol 2011, 45(2):261-269.

44. Aldonyte $R$, Jansson $L$, Janciauskiene $S$ : Concentration-dependent effects of native and polymerised alpha1-antitrypsin on primary human monocytes, in vitro. BMC Cell Biol 2004, 5:11

45. Aldonyte $\mathrm{R}$, Jansson $\mathrm{L}$, Ljungberg $\mathrm{O}$, Larsson $\mathrm{S}$, Janciauskiene $\mathrm{S}$ : Polymerized alpha-antitrypsin is present on lung vascular endothelium. New insights into the biological significance of alpha-antitrypsin polymerization. Histopathology 2004, 45(6):587-592. 
46. Yende S, Waterer GW, Tolley EA, Newman AB, Bauer DC, Taaffe DR, Jensen R, Crapo R, Rubin S, Nevitt M, Simonsick EM, Satterfield S, Harris T, Kritchevsky SB: Inflammatory markers are associated with ventilatory limitation and muscle dysfunction in obstructive lung disease in well functioning elderly subjects. Thorax 2006, 61(1):10-16.

47. Eagan TML, Ueland T, Wagner PD, Hardie JA, Mollnes TE, Damås JK, Aukrust P, Bakke PS: Systemic inflammatory markers in COPD: results from the Bergen COPD Cohort Study. Eur Respir J 2010, 35(3):540-548.

48. Duckers JM, Shale DJ, Stockley RA, Gale NS, Evans BA, Cockcroft JR, Bolton CE: Cardiovascular and musculskeletal co-morbidities in patients with alpha 1 antitrypsin deficiency. Respir Res 2010, 11:173.

49. Ahlgren AR, Piitulainen E, Sonesson B, Lanne T: Changes in aortic wall stiffness in men with alpha 1-antitrypsin deficiency. Eur J Vasc Endovasc Surg 1997, 14(4):252-257.

50. Talmud PJ, Martin S, Steiner G, Flavell DM, Whitehouse DB, Nagl S, Jackson R, Taskinen MR, Frick MH, Nieminen MS, Kesaniemi YA, Pasternack A, Humphries SE, Syvanne M: Progression of atherosclerosis is associated with variation in the alpha1-antitrypsin gene. Arterioscler Thromb Vasc Biol 2003, 23(4):644-649.

51. Stakisaitis D, Basys V, Benetis R: Does alpha-1-proteinase inhibitor play a protective role in coronary atherosclerosis? Med Sci Monit 2001, 7(4):701-711.

52. Wood A, Simmonds M, Bayley D, Newby P, Gough S, Stockley R: The TNFalpha gene relates to clinical phenotype in alpha-1-antitrypsin deficiency. Respir Res 2008, 9(1):52.

53. Barreiro E, Schols AM, Polkey MI, Galdiz JB, Gosker HR, Swallow EB, Coronell C, Gea J: Cytokine Profile in Quadriceps Muscles of Patients with Severe Chronic Obstructive Pulmonary Disease. Thorax 2008, 63:100-107.

54. Montes de Oca M, Torres SH, De Sanctis J, Mata A, Hernandez N, Talamo C: Skeletal muscle inflammation and nitric oxide in patients with COPD. Eur Respir J 2005, 26(3):390-397.

55. Gouzi F, Préfaut C, Abdellaoui A, Roudier E, De Rigal P, Molinari N, Laoudj-Chenivesse D, Mercier J, Birot O, Hayot M: Blunted muscle angiogenic training-response in copd patients versus sedentary controls. Eur Respir J 2012, 41(4):806-814.

56. Koechlin C, Maltais F, Saey D, Michaud A, LeBlanc P, Hayot M, Prefaut C: Hypoxaemia enhances peripheral muscle oxidative stress in chronic obstructive pulmonary disease. Thorax 2005, 60(10):834-841.

57. Petersen AM, Penkowa M, Iversen M, Frydelund-Larsen L, Andersen $J L$, Mortensen J, Lange P, Pedersen BK: Elevated levels of IL-18 in plasma and skeletal muscle in chronic obstructive pulmonary disease. Lung 2007, 185(3):161-171.

58. van der Vlist J, Janssen TW: The potential anti-inflammatory effect of exercise in chronic obstructive pulmonary disease. Respiration 2010, 79(2):160-174

59. Ploeger HE, Takken T, De Greef MH, Timmons BW: The effects of acute and chronic exercise on inflammatory markers in children and adults with a chronic inflammatory disease: a systematic review. Exerc Immunol Rev 2009, 15:6-41.

60. Dowson LJ, Newall C, Guest PJ, Hill SL, Stockley RA: Exercise capacity predicts health status in alpha(1)-antitrypsin deficiency. Am J Respir Crit Care Med 2001, 163(4):936-941.

\section{Submit your next manuscript to BioMed Central and take full advantage of:}

- Convenient online submission

- Thorough peer review

- No space constraints or color figure charges

- Immediate publication on acceptance

- Inclusion in PubMed, CAS, Scopus and Google Scholar

- Research which is freely available for redistribution

Submit your manuscript at www.biomedcentral.com/submit
C Biomed Central 